\title{
Testicular Mixed Germ Cell Tumor Diagnosed on Fine Needle Aspiration Cytology - Is It Reliable?
}

\author{
Richa Garg ${ }^{1}$, Sunil Gupta ${ }^{2}$ \\ ${ }^{1}$ MBBS, DNB Pathology, MNAMS, Sahu Rameshwar Saran Kothiwal Hospital, Kanth Road, Moradabad- 244001, India \\ ${ }^{2}$ MBBS, MS, Sahu Rameshwar Saran Kothiwal Hospital, Kanth Road, Moradabad- 244001, India
}

\begin{abstract}
Mixed germ cell tumors are the tumors composed of two or more types. The present case reports a left sided testicular mixed germ cell tumor comprising of syncytiotrophoblastic cells, teratoma and yolk sac components, which could be diagnosed on FNAC performed in a 25 years old male. This diagnosis offers a diagnostic challenge on FNAC but is reliable for further management. FNAC avoids the need for tissue biopsy and lessen the reporting time which is important where the oncologist needs time to counsel the patient and to plan the rapid mode of treatment according to the nature of the tumor.
\end{abstract}

Keywords: Testis, mixed germ cell tumor, teratoma, yolk sac tumor, FNAC

\section{Introduction}

FNAC is being used increasingly to diagnose tumors from various body parts. However, its use in the diagnosis of testicular tumors has always been controversial, possibly due to the fear of implantation and dissemination of tumor by needle trauma. Also, lack of proper information on interstitial tissue and tubular basement membrane on FNAC smears limits its use for testicular neoplasms $[1,2]$. However, FNAC offers various advantages over open biopsy as the procedure is non-traumatic, easy to carry out and avoids delay of diagnosis [3]. It is also an effective tool for diagnosis of testicular germ cell tumors (GCT's) that comprise approximately 95\% of testicular neoplasms [4]. Review of literature had shown that though few case reports of metastatic mixed germ cell tumor of testis have been reported so far none has been diagnosed as primarily testicular mixed germ cell tumor on FNAC.

\section{Case Report}

A 25 years old male patient presented with painless left testicular mass measuring $8 \times 6 \times 5 \mathrm{cms}$ that gradually increased in size over six months (Fig1). Clinical differentials were tuberculosis versus tumor. Ultrasound report showed necrotic and focal calcific areas. FNAC was advised as next diagnostic modality. FNAC was performed after taking written consent, under aseptic precautions using a 10.0-mL plastic syringe fitted with a 23 -gauge needle. Both wet-fixed and air-dried smears were made and stained by rapid Papanicolaou (pap) stain and Giemsa stain respectively. On light microscopy, the smears were highly cellular. The cells were moderately to highly pleomorphic and arranged in three dimensional tight clusters, loosely cohesive groups and irregular fragments. At some places, sheets of malignant round to oval cells with naked nuclei, scant cytoplasm, and inconspicuous nucleoli resembling neuroectoderm were present (Fig 2a). At other areas, few clusters of small hyperchromatic cells resembling blastema were noted (Fig 2b). Fetal like mesenchyme with tightly packed spindle cells were seen (Fig 2c). Syncytiotrophoblastic giant cells with abundant cytoplasm, cytoplasmic processes and multiple nuclei were also observed (Fig 2d). In two of the slides, pleomorphic cells were arranged predominantly in papillaroid fragments and complex architectural pattern (Fig 2e). Basement membrane like material with entangled tumor cells was observed in these slides (Fig 2e inset). The tumor cells in papillaroid fragments were characterised with vesicular nuclei, small nucleoli, and moderate amount of pale cytoplasm with presence of cytoplasmic microvacuoles (Fig 2f) Background was largely haemorrhagic, focally necrotic and mucoid in one of the slides. In light of these findings, the diagnosis proposed was left testicular mixed germ cell tumor comprising of syncytiotrophoblastic cells, teratomatous and yolk sac components. Teratomatous component could be evident by presence of epithelial, blastemal and mesenchymal structures. The presence of three dimensional complex clusters, papillaroid fragments with tumor cells having vacuolated cytoplasm, presence of basement membrane like material and mucoid background suggested the possibility of yolk sac component. The patient was further suggested for serum hormonal investigations for beta human choriogonadotropin (BhCG), alpha fetoprotein (AFP) and lactate dehydrogenase (LDH). The hormonal profile came out as serum AFP - 645ng/ml (raised), $\beta \mathrm{HCG}$ $132.10 \mathrm{mIU} / \mathrm{ml}$ (raised) and $\mathrm{LDH}$ was $245 \mathrm{IU} / \mathrm{L}$ (normal) which corresponded with the proposed diagnosis. No lymph nodes were enlarged. Left orchidectomy was planned as a modality of treatment following cytodiagnosis. The patient was diagnosed with left Testicular mixed germ cell tumor (70\% immature teratoma $30 \%$ yolk sac tumor) on histopathology (Fig 3).

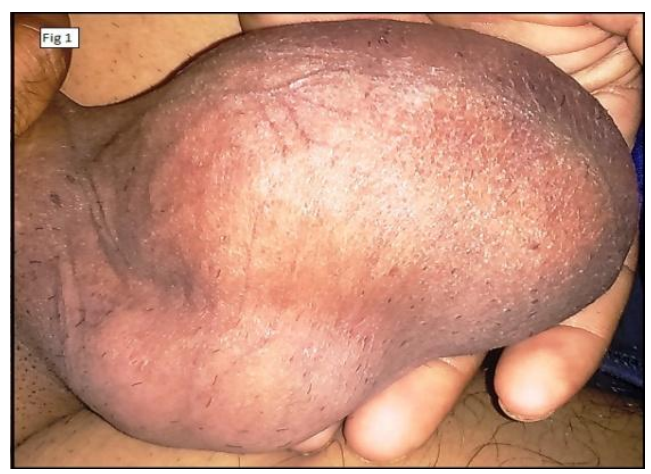

Figure 1: Enlarged painless left testicular mass 


\section{International Journal of Science and Research (IJSR) \\ ISSN: 2319-7064}

ResearchGate Impact Factor (2018): 0.28 | SJIF (2018): 7.426

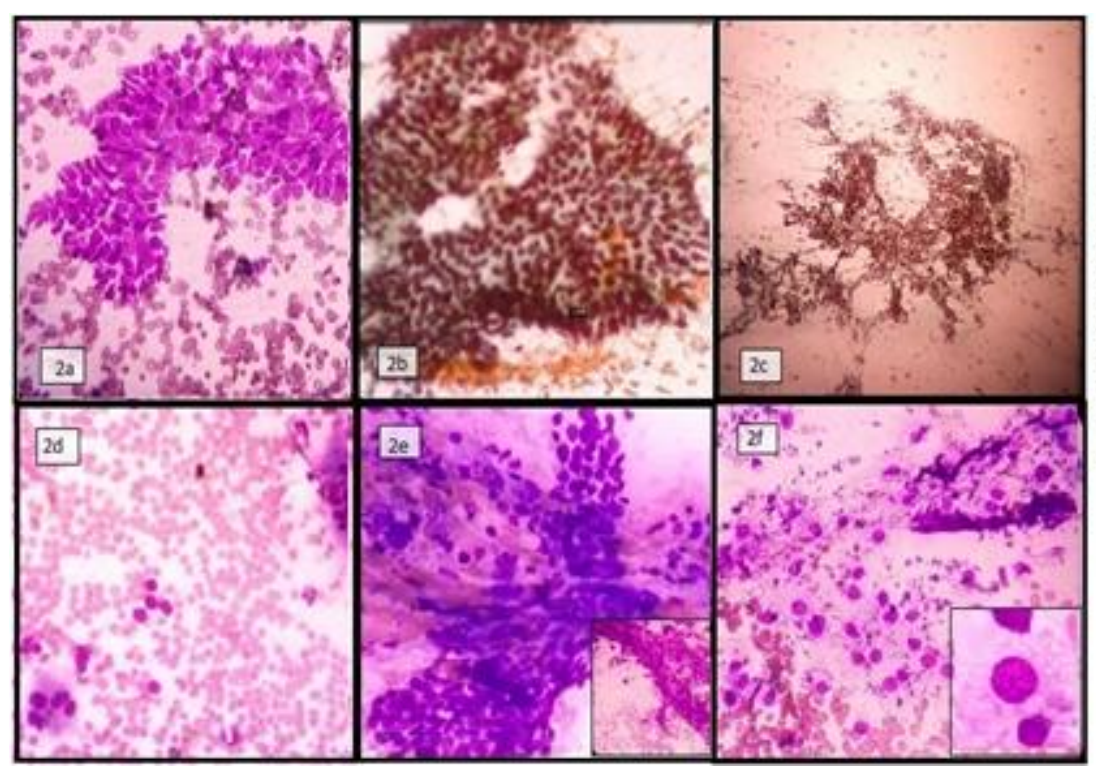

Fig2 (a) Giemsa 40X. Neuroectodem, cells arranged in clusters having high $\mathrm{N} / \mathrm{C}$ ratio, dispersed chromatin, inconspicuous nucleoli. Fig2(b) Pap stain 40X. Undifferentiated blastema. Fig2(c) Pap stain 40X. Mesenchyme with spindle cells. Fig2(d) Giemsa 40X. Syncytiotrophoblastic cells with multiple nuclei. Fig 2(e) Giemsa $40 \mathrm{X}$. Cells arranged in papillroid fragment, inset shows basement membrane like material with entangled cells. Fig2(f) Giemsa 40X. Loosely cohesive group of vacuolated cells, inset shows a single cell with microvacuoles.

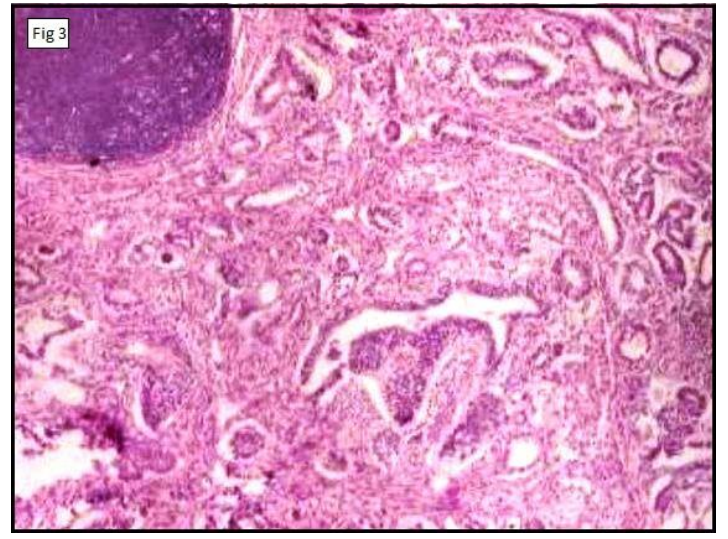

Figure 3: Undifferentiated blastemal cells and mesenchyme on histopathology, H\&E (40X)

\section{Discussion}

Testicular tumors constitute one of the most common tumors of men with incidence of 3-4 cases per 1,00,000 males each year (4). Majority of them originate from germ cells and contain more than one tumour type comprising of seminoma, embryonal carcinoma, yolk sac tumor, teratoma and choriocarcinoma. The most common mixed germ cell tumor comprises of teratoma and embryonal carcinoma (5). Most germ cell tumours occur between the ages of 20 and 50 years [6]. Patients present with painless or painful testicular swelling. Cryptorchid testis is at a higher risk for tumour development [7]. Embryologically, testicular tumour cells are totipotent germ cells that follow abnormal pathways of differentiation resulting into either seminoma or embryonal carcinoma. Embryonal cells give rise to teratoma by intraembryonic differentiation while yolk sac tumour or choriocarcinoma are produced by extra-embryonic differentiation [8, 9]. FNAC acts as an initial approach to diagnosis over biopsy for benign from malignant conditions. A careful and extensive examination of FNAC slides should be performed to identify the relatively minor component to make the diagnosis of mixed germ cell tumor. The present case showed the predominant component teratoma (70\% on histopathology) and minor component as yolk sac tumor (30\% on histopathology). However, exact percentage of the components cannot be determined on FNAC and histopathology remains the gold standard for reporting it Elevation of $\beta \mathrm{HCG}$ is observed in choriocarcinoma, seminoma and tumors associated with syncytiotrophoblastic cells as in our case. Raised AFP is associated with yolk sac tumor in the present case. Prognostically, presence of seminomatous component offers a favourable prognosis than non seminomatous mixed germ cell tumor [7]. Also, the presence of teratoma and yolk sac tumour is associated with a lower incidence of metastasis following orchiectomy in clinical stage I disease [6]. Distinction of germ cell tumors from non-neoplastic lesions like tuberculosis and distinction among various subtypes of germ cell tumors may have an important therapeutic implication and thus be crucial in planning the proper management of the patient.

\section{Conclusion}

FNAC helps to differentiate testicular non-tumorous conditions from tumorous condition. It proceeds for a prompt therapy, avoids lengthy hospitalizations and needless resection in some cases like testicular lymphoma which can be cured by chemotherapy. The best possible detailed information of testicular tumor on FNAC can guide the oncologist towards the best mode of treatment. Early identification and treatment is essential for achieving long term survival. The present case was diagnosed on FNAC which is an effective, rapid and reliable procedure for the diagnosis of testicular mixed germ cell tumor.

\section{Conflicts of interest: None}

\section{References}

[1] Hajdu SJ, Melamed MR. Limitations of aspiration cytology in the diagnosis of primary neoplasms. Acta Cytol. 1984; 28:337-45. [PubMed]

[2] Highman WJ, Oliver RT. Diagnosis of metastasis from testicular germ cell tumors using fine needle aspiration cytology. J Clin Pathol. 1987; 40:1324-33. [PubMed]

[3] Gottschalk-Sabag S, Glick T, Weiss DB. Fine needle aspiration of the testis and correlation with testicular open biopsy. Acta Cytol. 1993; 37:67-72. [PubMed]

\section{Volume 8 Issue 8, August 2019}




\section{International Journal of Science and Research (IJSR) \\ ISSN: 2319-7064}

ResearchGate Impact Factor (2018): 0.28 | SJIF (2018): 7.426

[4] Sumat K, Rumana M, Parveen Shah. Clinicopathological characteristics of testicular tumors. Clin Pathol 2017, 1(1): 000106

[5] Lee SC, Kim KH, Kim SH, Lee NM, Park HS, Won JH. Mixed testicular germ cell tumor presenting as metastatic pure choriocarcinoma involving multiple lung metastases that was effectively treated with highdose chemotherapy. Cancer Res Treat. 2009 Dec; 41(4): 229-232.

[6] Tumours of the testis and paratesticular tissue In, Eble JN, Sauter G, Epstein JI, Sesterhenn IA, editors, Pathology and Genetics of Tumours of the Urinary System and Male Genital Organs. Lyon, IARC Press, 2004, p, 220-250

[7] B D Kashyapi, J N Kulkarni. Testicular cancer: Current management.

www.bhj.org.in/journal/1999_4103_july99/sp_437.htm

[8] Dixon FH, Moore RA. Tumors of the male sex organs. In: Atlas of tumor pathology.Washington, EC: AFIP. 1952.

[9] Mostofi FK. Testicular tumors: epidemiologic, etiologic and pathologic features. Cancer 1973; 32: 1186. 